\section{Características genéticas de las poblaciones de Aedes aegypti en Río de Janeiro}

Río de Janeiro es una de las ciudades más densamente pobladas de Brasil y uno de los centros económicos y turísticos más activos de ese país. Por las numerosas vías de comunicación terrestres, aéreas y marítimas, esta ciudad se considera una importante puerta de entrada del virus del dengue y de su vector principal, el mosquito Aedes aegypti.

El comportamiento de $A$. aegypti en Brasil se ha descrito como altamente antropófilo y endófilo y su hábitat larvario preferido son los recipientes artificiales. Diferentes autores han descrito diversos grados de variabilidad genética de esta especie en Brasil. Mediante técnicas de genética poblacional basadas en el estudio de isoenzimas se ha podido establecer que las condiciones ambientales y la intervención humana (como la urbanización y las actividades de control vectorial) influyen en el grado de diferenciación genética de las poblaciones de mosquitos y esta se manifiesta tanto espacial como temporalmente.

En este artículo se informa de los resultados de un estudio de la variación genética, tanto geográfica como temporal, del mosquito $A$. aegypti mediante el empleo de marcadores isoenzimáticos. Para ello se recolectaron muestras de larvas de mosquitos en diversos puntos de la ciudad de Río de Janeiro entre diciembre de 2002 y diciembre de 2003 . Una vez criadas hasta el estadio adulto en insectarios con condiciones controladas, se analizaron entre 14 y 48 individuos de cada sitio de recolecta. Las 10 enzimas estudiadas fueron: glucosa-isomerasa de fosfato (EC 5.3.1.9), aspartato-aminotransferasas (EC 2.6.1.1), glicerol-deshidrogenasa de fosfato (EC 1.1.1.8), hexocinasas (EC 2.7.1.1), malato-deshidrogenasa (EC 1.1.1.37), enzima málica (EC 1.1.1.40) y fosfoglucomutasa (EC 2.7.5.1). La diferenciación genética entre las muestras se estimó mediante el valor de $P$ asociado con el índice de fijación $\left(F_{\mathrm{ST}}\right)$.

El análisis realizado, tanto desde el punto de vista espacial como temporal, demostró que hay una elevada diferenciación genética entre las muestras de mosquito tomadas en varios distritos de la ciudad que se encontraban de 3,5 a $38,5 \mathrm{~km}$ de distancia entre sí. Esto indica que la tasa de migración de estas poblaciones es baja. En la mayoría de los sitios de recolecta, las poblaciones de mosquito estaban bien diferenciadas, lo que puede reflejar una baja dispersión de esas poblaciones. Este patrón se mostró menos acentuado durante la temporada seca, ya que la diferenciación fue menor. En general, las muestras recolectadas en la temporada lluviosa tuvieron una mayor diferenciación que las colectadas en la época de sequía.

Las migraciones de las poblaciones de mosquitos que habitaban las áreas que no habían sido fumigadas, como los barrios bajos de la ciudad, resultaron suficientemente intensas para contrarrestar la deriva genética y la diferenciación entre las poblaciones, especialmente al inicio de la temporada de seca. Las poblaciones de $A$. aegypti que se encontraron en los recipientes de almacenamiento de agua, principalmente en los barrios bajos, presentaron por lo general un menor grado de diferenciación genética que las encontradas en los reservorios temporales.

Al comparar el perfil isoenzimático de $A$. aegypti a lo largo de la ruta principal que atraviesa Río de Janeiro, se encontró una abundante diferenciación genética, lo que indica que esta especie no sigue la ruta de las carreteras y ferrocarriles para diseminarse $\mathrm{o}$, al menos, que las vías de transporte no provocan la homogenización genética de las poblaciones que habitan en la ciudad.

Estos resultados indican que las poblaciones de $A$. aegypti en Río de Janeiro están muy estructuradas y tienen un escaso intercambio genético entre sí. La estructuración genética fue mayor en la época de lluvia que en la época seca, lo que puede indicar que el vector no migra de un distrito a otro en esa época del año en que han aparecido las principales epidemias de dengue en la ciudad. (Da CostaRibeiro MCV, Lourenço-de-Oliveira R, Failloux AB. Geographic and temporal genetic patterns of Aedes aegypti populations in Rio de Janeiro, Brazil. Trop Med Int Health. 2006;11:1276.)

\section{El enfoque de reducción del daño en la lucha contra el alcoholismo en Brasil}

El consumo de bebidas alcohólicas es un problema importante de salud pública en Brasil. Según el Centro Brasileño de Información sobre Drogas Psicotrópicas, aproximadamente $68,7 \%$ de la población general del país ha probado una bebida alcohólica en algún momento de su vida y $11,2 \%$ es adicta al alcohol. El costo social del daño ocasio- 